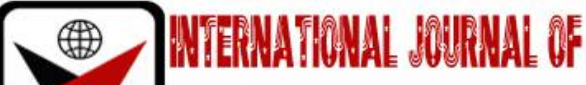

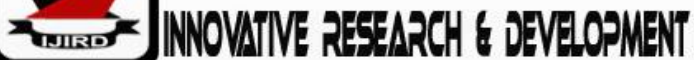

ISSN 2278-0211 (Online)

\section{Investigation of Simulium Specie Infestation in Veritas University Metropolis, Abuja, Nigeria}

\author{
Dr. Okoi Enang Effiom \\ Associate Professor, Department of Biological Sciences, \\ Veritas University, Abuja, Nigeria \\ Chinyere Gift Nwosu \\ Graduate Assistant, Department of Biological Sciences \\ Veritas University, Abuja, Nigeria
}

\begin{abstract}
:
Simuliumdamnosum, commonly known as black flies, are the mechanical vectors of Onchocerca volvulus. Onchocerciasis (or river blindness), is a disease caused by this specie of microfilariae in humans in the tropical and subtropical regions of the globe. Critical public health and socio-economic problems arise due to Onchocercasis, an insidious non-fatal filarial infection. With itching and disfiguring of skin with nodules on bony areas, serious eye lesions even blindness happen due to this. This study therefore investigated Simuliumspecie infestation in the campus of Veritas University Abuja and its environs with a view to establishing the possible occurrence of river blindness disease in the area. The study involved identification of possible breeding sites, searching and collecting eggs, larvae and adult blackflies, identification of the species through examination of the eggs, larvae, pupae and adult flies and dissection of the adults for presence of microfilariae of Onchocerca volvulus. The result showed that 365 adult flies were caught which were identified into 244 females and 131 males, 209 eggs and 113 larvae were also collected. The presence of the eggs, larvae and adult blackflies indicated not only their presence but also the active reproduction of these flies in the environment. The adult flies were then dissected for presence of microfilariae.60/49.6\% of the 131 adults Simuliumdamnosum complex were found to be infected with microfilariae in their head and thoracic regions meaning that the Simulium species present are infective and can bring about river blindness disease in the area and should therefore be checked.
\end{abstract}

Keywords: Investigation, simulium, infestation, onchocerciasis, veritas metropolis

\section{Introduction}

Morbidity and mortality happen every year due to insect-transmitted diseases in tropical countries. African countries, especially river blindness (onchocerciasis) has been caused by Simulium species transmit Onchocerca volvulus (5). Many problems of skins and eyes happen due to the parasite of onchocerciasis $(4,23)$. Onchocerciasis has been described as an insidious non-fatal filarial infection that causes not only blindness but also life-long human suffering and grave socio-economic problems (23). The disease is commonly called 'river blindness', because the blackflies which transmit the disease are strictly associated with riverine areas. The disease affects millions of people in the world, but mostly in Africa centuries, and therefore it is considered to be of high economic importance (19). According to WHO (14) report, Nigeria has the highest number of onchocerciasis victims than any other country in the world, and makes about 100,000 out of the 268,000 global known cases. Infection has spread on 37-86 million people in 35 Onchocerciasis endemic countries of Tropical Africa, Latin America and Yemen are infected with Onchocerca volvulus, while 2 million and 50,000 of these exposed individuals are blind and visually-impaired, respectively[21,19]. One quarter of the global infection has been caused by onchocerciasis in Nigeria (14). Landslides of rivers and streams had been noticed for immense morbidity of the infection in the country (9). Most rivers and fast flowing streams had become breeding sites for Simuliumdamnosum complex $(22,11)$. More than 20 million people infected, and millions blinded in West Africa and South America (17).A study by Hazarika et al., (8) found that even in countries like India, where the parasitic load of Onchocerca volvulus is low, Simulium can still be found to bite and crawl on the skin of individuals, causing intolerable nuisance. Similarly, besides their painful bites which often lead to loss of significant amount of blood, the wounds can also carry secondary infections by serving as route for bacteria, viruses, protozoa, nematodes, etc., which the fly sometimes carry on their bodies (26).Furthermore, in humans, the bites of some blackfly species can cause allergic reactions known as "blackfly fever" or simuliotoxicosis. This condition is characterized by swelling, itching, haemorrhage and oedema which in severe cases, requires medical attention (17). Onchocerciasis has equally been regarded as a disease of rural areas, even though it is found also in urban centers due to rural-urban migration. Those most at risk of contracting the infection are mostly travelers, the missionaries and peace-corps volunteers who are often exposed to bites of black-fly in endemic areas. 
The incidence of the disease increases with increase in human activities along the river valleys, which are the habitats of Simulium vectors. Human activities which could boost the infestation of Simulium have been identified as bathing, swimming, farming, hunting, and other recreational activities carried out along and in the vicinity of the streams. The effects of onchocercal infection are not only reflected in individuals, but also on the economy of the countries at large, since the disease normally leave debilitating effects on humans, incapacitating a huge number of working population, and thus render them incapable of working again.

Some of the ways of eradicating this vector-borne infection include destruction of the larvae of the vector (the blackfly), destruction of the adult parasite (Onchocercusvolvolus) in hosts' body, and prevention of vector-host contacts $(12,26)$. Various synthetic chemical agents have been used to destroy the larvae of black flies, but this chemical control method does not usually produce impressive result (8). Besides, this effort requires treatment of all potential breeding sites or rivers with suitable insecticides. But, the major problem with such control method is that non-target organisms are also affected, thus leaving a negative feedback on the ecosystem (16). Secondly, such methods are daunted when a large area is infested with blackfly larvae. Although control of adult blackflies is said to be most desirable, it is less feasible because of their frequent migration and the long flight range of the vector (5).

Simuliids-biting generally occurs outdoor during daytime hours, and prefer to bite the lower exposed body parts $(20,8)$. Different simuliid species may have their own preferred biting periods $(20)$.

In animals, blackflies have also been incriminated in the spread of leucocytozoonosis, bovine onchocercosis, the cytoplasmic polyhedrosis virus, the iridescent virus and vesicular stomatitis virus (17).

Deaths of animals, especially livestocks had been happened due to attack of blackflies like tsetseflies (Glossinaspp). Many economic slowdowns had been caused by haematophagous Simulium species (28). Many studied also had been conducted South Africa (27).Other reports confirmed that cows can lose their udders and sheep their ears as a result of secondary infections arising from blackfly wounds (17). Ground larviciding had been mentioned as one of the most effective means for control. This concentrates containing up to $33 \%$ DDT have given the best results. They have been applied at variable rates between $0.03 \mathrm{ppm} / 30 \mathrm{~min}$ and $0.5 \mathrm{ppm} / 30 \mathrm{~min}$, depending on local conditions, and it has been found that at these levels, DDT has proved to be non-toxic to fish. Rivers need to be disinfected once in 7-10 days even throughout the rainy season, and for periods of not less than 3 months.

Crosskey, (15) in his study highlighted that the presence of hard Precambrian with rocks, outcrops in the streambeds as forming favorable breeding sites for especially Simuliumdamnosum complex. The challenge associated any form of control involving the use of aircraft is expensiveness, and might well be precluded on these grounds, except in exceptional circumstances. Female adults of some simuliid species generally act as vectors of some parasites and pathogens, like Onchocerca spp. in humans and cattle and Leucocytozoon spp. in birds (28). Generally, America, Mexico, Yemen, Brazil, Venezuela, Ecuador, Colombia and Africa (13) had been seen most suffering nations due to the flies. West Africa and also in some countries in Eastern and Southern Africa, Simuliumdamnosum has been noticed as a major vector which has been mentioned by Mustapha et al., $(18,9)$. Most of the previous researches had focused on the northern part of the Nigeria (11).

In 1974, World Health organization (WHO) had laughed Onchocerciasis Control Programme (OCP). It started with the control of Onchocerciasis through eradication of the black fly vector in seven endemic countries of West Africa including Nigeria, using spraying dichlorodiphenyltrichloroethane (DDT) mainly in river breeding sites. But due to high toxic agents many side effects had been noticed inside human body which control the scourge of onchocerciasis using diethyl carbomazine $(7,27)$. Later, in 1987, ivermectin (Mectizan) had been introduced by a pharmaceutical firm (Merck) as a safest measurement (14). 32 endemics States and the Federal Capital Territory (FCT) (19) started the mass ivermectin (Mectizan) treatment of onchocerciasis.

\section{Materials and Methods}

\subsection{Study Area}

This study was carried out in Veritas University Campus, Bwari Area Council, Abuja, and its environs, Zuma I and II, and Garba, from February to July. Bwari Area Council is one of the six Area Councils in the Federal Capital Territory in the North Central Geopolitical Region of Nigera. Veritas University was founded by the Catholic Bishops Conference of Nigeria. However, the University commenced admission of students in October Nigeria, in 2008 and today it has a population of over 3,000 people. Bwari Area Council where the Veritas University is located is found in the North Eastern part of the F. C. T., and is situated between latitude 7023' 0" North of the Equator and Longitude 9017'0" East with a vast land of $1100 \mathrm{~km}^{2}$. It has a guinea savannah type of vegetation, with raining season stretching from April to October. From November to March, dry season has been noticed and the temperature ranges from $30-37^{\circ} \mathrm{C}$ yearly with the highest temperature experienced in the month of March. The indigenes of Bwari Area Council are the Gbagi's and Gwari's and they are mostly farmers by occupation.

\subsection{Sources and Method of Simulium Specimen Collection}

Samples were collected from the fast-flowing streams that transverse the Veritas University Campus and flowing behind the male hostels, the auditorium and the Vice Chancellor's office, and the ones are also found in Zuma I, Zuma II and Garba. The streams were marked A, B, C, D, E and F, respectively, for the purpose of this research.

The Simulium species were collected by scooping the stream vegetation and those at the shore or bank with butterfly nets. The Simulium specimens caught were immobilized by dipping the scooping nets in water, and removing 
same after approximately 10 sec., after which the flies were handpicked, and dropped in labeled specimen bottles, containing formalin, and conveyed to the laboratory.

\subsection{Sex and Species Identification of Simulium}

The adult blackflies collected were subjected to sex and species identification using the morphometric and cytological identification keys described by Crosskey (15), Meredith et al., (10) and Post et al., (25). Using a combination of these keys, only Simuliumdamnosum complex was identified in the collection based on the possession of tubercles on the dorsal region of their larvae, possession of scales on the thoracic proleg as well as chromosomal variation in the $6^{\text {th }}$ and $7^{\text {th }}$ instar larvae of the blackfly since according to Post et al., (25) $6^{\text {th }}$ and $7^{\text {th }}$ instar larvae give better information on the chromosomes. Ventral dissection of the head, thorax and abdomen was done under a dissecting microscope. The polytene chromosomes were prepared from the larval silk glands and examined using the oil immersion lens. The banding patterns of the three pairs of chromosomes were accordingly scored. The sexes of the Simuliumdamnosum were identified by the fact that male adults possess toothed mandibles and maxillae, eyes which are much larger touching above antennae, hence described as holoptic, compact and inconspicuous male Terminalia, a blacker body appearance and a reflective silvery mark on their abdomen to aid recognition by the female partner during mating The female adults were identified by possession of larger mandibles bearing a row teeth for cutting and bloodletting as described by Crosskey (15), possession of smaller ommatidia which makeup the eyes, possession of dichoptic eyes (in other words, eyes which are well separated from the antennae that lie below the eyes), possession of single subspherical spermathecal and a grayer body appearance.

\subsection{Dissection and Microscopic Examination Of The Adult Females Flies}

The head, thorax, and abdomen of the identified female blackflies were dissected using dissecting microscope and pins, and examined for the presence of microfilariae of Onchocerca volvulus using X10 objectives lens. This process was repeated with all the females. The larval stages $\left(\mathrm{L}_{2}-\mathrm{L}_{3}\right)$ of Onchocerca volvulus were isolated. The Microfilariae isolated from each morphological segment of the flies dissected were stained with haematoxylin, and then identified, counted and recorded appropriately.

\section{Results}

\subsection{Result of Simulium Collection}

Sample collection was carried between February and July, 2019. A total of 244 adult Simulium were collected during the field survey of the six streams, and this number comprised of $131 / 53.7 \%$ females and $113 / 46.3 \%$ males. Also harvested were 209 eggs and 113 larvae of the flies (Table 1).

\begin{tabular}{|c|c|c|c|c|c|}
\hline Location & Time & Eggs & Larvae & \multicolumn{2}{|c|}{$\begin{array}{c}\text { Adult Flies } \\
\text { Male Female }\end{array}$} \\
\hline Stream A & Feb-July & 25 & 19 & 24 & 28 \\
\hline Stream B & Feb-July & 66 & 20 & 20 & 26 \\
\hline Stream C & Feb-July & 30 & 22 & 23 & 23 \\
Stream D & Feb-July & 28 & 21 & 17 & 20 \\
Stream E & Feb-July & 42 & 16 & 14 & 18 \\
Stream F & Feb-July & 36 & 15 & 13 & 16 \\
\hline Total & Feb-July & 209 & 113 & 113 & 131 \\
\hline
\end{tabular}

Table 1: The Number of Eggs, Larvae and Adult Simulium Flies Collected During the Study

Key: Stream A = the stream behind the Vice Chancellors office; Stream B = the stream flowing from behind the Auditorium; Stream C = the stream behind the male Hostels; Stream D = the stream in Zuma I village; Stream E = the stream in Zuma II village; Stream; F = the stream in Garba village.

\subsection{Result of Simuliumdamnosum dissection for microfilaria}

The result of dissection of the different body regions of the 131 female adult Simuliumdamnosum showed that only the heads region of $23 / 17.6 \%$ blackflies contained onchocerca microfilariae, $37 / 28.2 \%$ were found with onchocerca microfilariae in their thorax while the abdomen had none (Table 2).

\begin{tabular}{|c|c|cc|}
\hline Body Parts & Positive & Negative & Total \\
\hline Head & $23 / 17.6 \%$ & $98 / 80,9 \%$ & 131 \\
\hline Thorax & $37 / 28.2 \%$ & $84 / 69.4 \%$ & 131 \\
\hline Abdomen & 0 & $131 / 100 \%$ & 131 \\
\hline Total & $60 / 49.7 \%$ & $313 / 250.3 \%$ & $393 / 300 \%$ \\
\hline
\end{tabular}

Table 2: The Result of Dissection of the Different Body Regions of the

Flies for the Presence of Microfilariae of 0 . Voluvulus

The monthly collections of Simuliumdamnosum complex specie showed that while 39 eggs, 21 larvae and 29 adults were collected in the month of February, in March 43 eggs, 28 larvae and 57 adults were collected. In April 48 eggs, 26 
larvae and 75 adults' blackflies were collected whereas in May 47 eggs, 24 larvae and 54 adults were obtained. Collection in June showed 32 eggs, 14 larvae and 24 adults Simuliumdamnosum while in July there were no eggs, no larvae but only 5 adults.

\begin{tabular}{|c|c|c|c|cc|}
\hline Month & Egg & Larvae & \multicolumn{2}{|c|}{$\begin{array}{c}\text { Adult } \\
\text { Female }\end{array}$} & \multicolumn{2}{|c|}{$\begin{array}{c}\text { Adult Total } \\
\text { Male }\end{array}$} \\
\hline February & 39 & 21 & 18 & 11 & 89 \\
\hline March & 43 & 24 & 33 & 28 & 128 \\
\hline April & 48 & 26 & 40 & 35 & 149 \\
\hline May & 47 & 28 & 26 & 24 & 125 \\
\hline June & 32 & 14 & 12 & 12 & 70 \\
\hline July & - & - & 2 & 3 & 5 \\
\hline Total & 209 & 113 & 131 & 113 & 566 \\
\hline
\end{tabular}

Table 3: Monthly Collections of Simulium Species

\section{Discussion}

The results obtained have shown that Simulium specie is exist in the streams on the campus of Veritas University, and streams in Zuma I, Zuma II and Garba, Simuliumdamnosum was identified as the species that exist in the streams surveyed, and no other species co-exist with it The black flies dissected and examined under the microscope for the presence of microfilariae of Onchocerca volvulus, of 131 female adults dissected 60/49.7\% were found infected with microfilariae in their head or thoracic regions. The proportion of Simuliumdamnosum complex found in the study area is a clear indication that the streams and the areas are highly infested with blackflies. The low number collected in the month of February can be attributable to the fact that there were no frequent human activities such as farming activities in and around the streams because it is usually human activities in a place that attract them. This assertion agreed with the finding of research conducted by (2) on the abundance of the Simulium species in the river Muvur, Mubi in Adamawa state, where he recorded 310 flies with 89 infected with O.volvulus. This research has equally confirmed earlier reports that the high numbers of Simulium in March and April may have been due to high level of farming activities and other human activities such as swimming and fishing all of which were ongoing in and around the river, besides, there was no rainfall. The contrary was the case in the onset of the rains in May and June because the rains normally come with violent windstorm which probably sweeps away the flies thereby making it difficult for their eggs and larvae of the fly to survive. Another factor that may have contributed to the reduced fly number in the month of July might be heavy rain falls and the accompanying windstorm which may have compelled the adult flies to flee from the streams to a more secured habitat to hide. It can also be argued that probably because the streams used in this study are shallow, therefore they were not able to adequately support the flies to breed abundantly. This observation has collaborated the findings of previous studies on the distribution of black flies in Bahia region of Brazil by Landeiro, et al., (1) they asserted that there is a relationship between the number of Simulium species and the size and depth of the breeding sites.

Besides onchocerciasis disease which is associated with infestation of Simuliumdamnosum, another fear about the presence of blackflies in the streams surveyed in Veritas University Campus, Zuma I, Zuma II and Garba is the possible existence in the area of another species of blackfly which attacks sheep and other forms of livestock and which together with the human species normally cause high economic losses through reduced efficiency of agricultural and industrial workers, in addition to interference in recreation and the consequent reduction of real estate values. It could be this kind of fear that made Njepuome et al., (19) and Tekie et al., (21) to warn that annoyance and discomfort caused by haematophagous Simulium species are severe enough to warrant large-scale control operations. How physical destruction of the teats of some cows and reduction in milk production of up to $35 \mathrm{~kg}$ milk per week per cow (30-50\% reduction) and 10-15\% reduction in egg production in poultry has been noticed in Western Nigeria had been highlighted by Basanex et al., (29). Moreover, the infections of udders and sheep their ears as a result of secondary infections caused from blackfly wounds (17) also have been mentioned. Similar calamity can befall animal farmers in this part of the world and that is why so something must be done urgently before it would be too late. Regarding the intimacy between Simulium species generally with warm-blooded vertebrates (humans and other mammals) it could be suggested that odors from these animal skin are attractive to blackflies. This may mean that blackflies have efficient olfactory system which plays important role in their host-detection process. Perhaps, the olfactory sensilla of the antennae of blackflies carry olfactory receptor neuron which is responsible for detecting human odors.

\section{Conclusion}

The study has established the presence of Simuliumdamnosum complex in the streams in Veritas University Campus and those in its environs, and the presence of microfilariae of $O$. volvulus in the head, thorax all of which are clear indications that both humans and livestock are potentially at risk of contracting onchocerciasis any moment since it is infected blackflies that transmit onchocerciasis to humans and other mammals, if human, recreational and agricultural activities proliferate in the area.

\section{Recommendations}

The use of biological control methods such as Bacillus thurengensisisraelensis(Bti) in the form of mosquito dunks or aquabacs can destroy the blackfly eggs in their breeding sites to prevent them from multiplying. Fumigation of the 
infested streams and streamline areas can help reduce Simulium infestation in the area. Periodic administration of metizan drug (an anti-filaria drug) can help prevent the development of the microfilariae in infected humans.

Human activities in and around the streams must be reduced to stop by discouraging individuals from visiting the streams but, if they must do so, then they must wear light-colour protective clothes.

\section{References}

i. Landeiro, V. I., Pepinelli, M., Hamada, N. (2009). Species Richness and Distribution of Blackflies (Diptera: Simuliidae) in the Chapada Diamantina Region, Bahia, Brazil. Neotropical Entomology, 28:332-339.

ii. Alexandra, Buitago-Guacaneme, Aura, Sotelo-Londono, Gabriel, A. Pinilla-Agudelo, Alexander, Garcia-Garcia, Ligia I. Moncada, Peter, H. Adler (2018). Abundance and Diversity of Blackflies (Diptera: Simuliidae) in rivers of the Andean Eastern Hills of Bogota (Colombia), and its relationship with water stream physicochemical variables. Universal Science 23(2):291-317.

iii. World Health Organization (WHO, 2013). Progress towards eliminating Onchocerciasis in the WHO Region of the Americas: verification by WHO of elimination of transmission in Colombia, Weekly Epidemiological Records, 88(36):381-388.

iv. Opara, K.N., Fagbemi, B.O, Ekwe, A., Okenu, D.M.N. (2005). Status of forest onchocerciasis in the Lower Croos River basin, Nigeria: Entomologic Profile after five years of ivermectin intervention. American Journal of Tropical Medicine and Hygiene, 73, 371-376.

v. Aisen, M.S.O., Imasuen, A.A., Wagbatsoma, V.A, Ayinde, B.A. (2004). Preliminary evaluation of the repellent activity of some plant essential oils against Simuliumdamnosum S.I., the vector of human onchocerciasis. International Journal of Tropical Insect Science, 24, 196-199.

vi. Cupp, E. W., Sauerbrey, M. and Richards, F. (2011). Elimination of HumanOchocerciasis. History of progress and current feasibility using Ivermectin (mectizan) monotherapy. ActaTropica, 120, 100-108.

vii. Forgione, M. (2006). Onchocerciasis. http://www.emedicine.com,16:67.

viii. Hazarika, S.S., Dhiman, B. Rabha, Bhola, R.K. and Singh, L. (2012). Repellent activity of some essential oils against Simulium species in India. Journal of Insect Science, 12, 1-9.

ix. Ibeh, 0.0., Nwoke, B.E.B., Adegoke, J.A, Mafuyai, H.B. (2006). Cytospecies identifications of vectors of human Onchocerciasis in Southeastern Nigeria. African Journal of Biotechnology, 5(19), 1813-1818.

X. Meredth, S. E. O., Cheke, R. A. and Garms, R. (1983). Variation and Distribution of forms of S.soubrense and sanctpauli in West Africa. Annals of Tropical Medicine and Parasitology, 77:627-640

xi. Ibeh, O. O., Nwoke, B. E. B., Adegoke, J. A. (2007). Distribution and Ecology of breeding sites of Simuliumdamnosum SI in Southeastern Primary health Zone of Nigeria. NigerianJournal of Parasitology, 28(1), 32-8.

xii. Killeen, G. F., Chitnins, N., Moore, S. J. and Okumu, F. O. (2000). Target product profile choices for intradomiciliary malaria vector control pesticide products: Repel or kill? Malaria Journal ,10, 207-216.

xiii. Malau, M.B. and James, D.B. (2009). Evaluation of larvicidal properties of some plant extracts on Simuliumdamnosum complex. The Internet Journal of Toxicology, 2, 1-6.

xiv. World Health Organization (WHO, 1995). Onchocerciasis and its control. Report of a WHO Expert Committee on Onchocerciasis. WHO Technical Report 852.

xv. Crosskey, R. W. (1981). A Review of Simuliumdamnosum S.L. and human Onchocerciasis in Nigeria, with special reference to cytographical distribution and development of Nigerian National Control Campaign. Trepenmedizin and Parasitologic 32:2 - 16.

xvi. Malau, M.B., Kutin, K., Kruppa, I.F., Brenya, R., Garms, R., James, D.B. (2006). Efficiency of Simuliumsanctipauli as a vector of Onchocerca volvulus in the forest zone of Ghana. Evaluation of larvicidal properties of some plant extracts on Simuliumdamnosum complex. Medical and Veterinary Entomology .The Internet Journal of Toxicology, 167-1 Control 73

xvii. Fisher, P. and Biittner, D. W. (2002). The Epidemiology of Onchocerciasis and the Long Term Impact of Existing Control Strategies on this Infection. Pp. 43-57 in Klei, T. R. and Rajan, T. V. (Eds). The Filaria. London, Kluwer Academic Publishers

xviii. Mustapha, A., Post, R.J., Enyong, P., Lines, J. (2004). A new cytotype of Simuliumsquamosum from South West Cameroon. Medical and Veterinary Entomology, 18, 296-300.

xix. Njepuome, N., Ogbu-Pearce, P., Okworonkwo, C. and Igbe, M. (2014). Controlling onchocerciasis: The Nigerian experience. The Internet Journal of Parasitic Diseases, 4(1), 1.

xx. Opara, K.N., L.P. Usip and Akpabio, E.E. (2008).Transmission dynamics of Simuliumdamnosum in rural communities of Akwa Ibom State, Nigeria. Journal of Vector Borne Diseases, 45, 225-230.

xxi. Tekie, A. H., Elhassan, E., Isiyaku, S., Amazigo, U. V., Bush, S., Noma, M., Cousens, S., Abiose, A. and Remme, J. H. (2014). Impact of long-term treatment of Onchocerciasis with ivermectin in Kaduna State, Nigeria: First evidence of the potential for the elimination in the operational area of the African Programme for Onchocerciasis control. Parasites and Vectors, 5(28), 6.

xxii. Usip, L.P.E., Udonsi, J.K., Ibanga, E.S., Opara, K.N. (2003).A survey of breeding sites and variation of Simuliumdamnosum in Ini L.G.A Of Akwa - Ibom Nigeria. Nigerian Journal of Parasitology, 24, 149 -154.

xxiii. Youssefi, M.R., Aminpour, A., Arabkhazaeli, F. (2008). Dermatitis caused by Simulium (Blackflies) bite. Iranian Journal of Parasitology, 3, 48-53.

xxiv. Kensey, Amaya (2003).ADW: Simuliumdamnosum, In: Animal Diversity Web. University of Michigan-Ann Arbor, Teresa, Friedrich (Editor). https://animaldiversity.org. 
xxv. Post, J.R., Onyenwe, E., Somiari, Stella B., Maluyai, Hayward (2011). A guide to S. damnosumcomplex (Diptera: Simullidae) in Nigeria, with a cytotaxonomic key for identification of the sibling species. Pathogens and Global Health 105(4):277-297.

xxvi. Usip, L.P.E, Opara, K.N., Ibanga, E.S, Atting, I.A. (2006). Longitudinal evaluation of repellent activity of Ocimiumgratissimum (Labiatae) volatile oil against Simuliumdamnosum. Memórias do Instituto Oswaldo Cruz, 101, 201-205.

xxvii. Cupp, E. W., Sauerbrey, M. and Richards, F. (2011). Elimination of HumanOchocerciasis. History of progress and current feasibility using Ivermectin (mectizan) monotherapy. ActaTropica, 120, 100-108.

xxviii. Thylefors, B. (2004). Eliminating onchocerciasis as a public health problem, Tropical Medicine \& International Health, 9, 1-3.

xxix. Basanez, M.G.,Collins, R.C., Porter, C.H., Little, M.P., Brandling-Bennett, D. (2002).Transmission intensity and the patterns of Onchocerca volvulus infection in human communities. American Society of Tropical Medicine and Hygiene, 67, 669-679. 